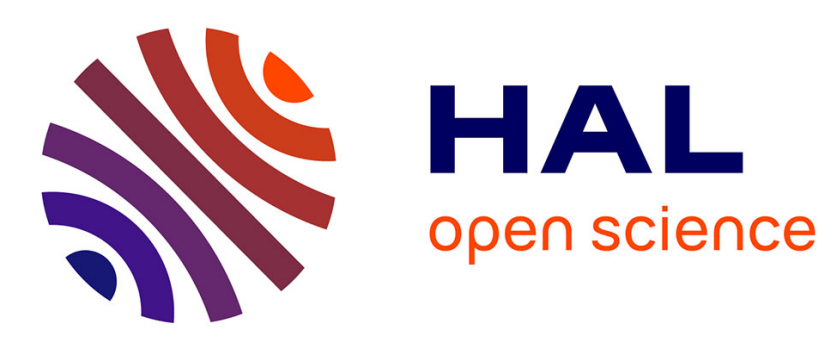

\title{
Group size, temperature and body size modulate the effects of social hierarchy on basal cortisol levels in fishes
}

Eduardo Bessa, Bastien Sadoul, David J. Mckenzie, Benjamin Geffroy

\section{To cite this version:}

Eduardo Bessa, Bastien Sadoul, David J. Mckenzie, Benjamin Geffroy. Group size, temperature and body size modulate the effects of social hierarchy on basal cortisol levels in fishes. Hormones and Behavior, 2021, 136, pp.105077. 10.1016/j.yhbeh.2021.105077 . hal-03411090

\section{HAL Id: hal-03411090 \\ https://hal.umontpellier.fr/hal-03411090}

Submitted on 21 Nov 2021

HAL is a multi-disciplinary open access archive for the deposit and dissemination of scientific research documents, whether they are published or not. The documents may come from teaching and research institutions in France or abroad, or from public or private research centers.
L'archive ouverte pluridisciplinaire HAL, est destinée au dépôt et à la diffusion de documents scientifiques de niveau recherche, publiés ou non, émanant des établissements d'enseignement et de recherche français ou étrangers, des laboratoires publics ou privés. 
1 Group size, temperature and body size modulate the effects of social hierarchy on basal cortisol levels in fishes

3 Eduardo Bessa ${ }^{1}$, Bastien Sadoul ${ }^{2}$, David J. Mckenzie $^{3}$ \& Benjamin Geffroy ${ }^{3 *}$

4

6

7

8

\author{
${ }^{1}$ Graduate Program in Ecology, Universidade de Brasília, Distrito Federal, Brazil \\ ${ }^{2}$ ESE, Ecology and Ecosystem Health, Institut Agro, INRAE, Rennes, France \\ ${ }^{3}$ MARBEC, Univ Montpellier, Ifremer, CNRS, IRD, Palavas-Les-Flots, France \\ *Corresponding author : bgeffroy@ifremer.fr
}

\title{
Abstract
}

Social rank in a structured society has been linked to basal levels of glucocorticoids in various species, with dominant individuals generally presenting lower levels than subordinates. The biotic and abiotic factors influencing glucocorticoids levels across social ranks are still, however, unclear in fishes. We investigated the influences of group size, fish size, sex, age, and reproduction type, plus water salinity and temperature, on the basal levels of cortisol, the major stress hormone in fishes. A phylogenetically controlled meta-analysis was performed on data from 72 studies over 22 species of fishes. As expected, dominants generally exhibited lower levels of cortisol than subordinates. More importantly, the strength of the correlation between cortisol and rank was modulated by three main factors, group size, environmental temperature, and fish size. Differences in basal cortisol between dominants and subordinates were significantly greater in small groups (dyadic contexts) when compared to larger groups. Differences between dominants and subordinates were also greater in temperate regions when compared to the tropics, and in species with larger body size. These results help to decipher the links among hierarchy, stress and metabolism in fishes.

Keywords: Stress; Aggressiveness; Sociality; Shoal; Meta-Analysis 


\section{Introduction}

34 Many animal societies are organized into hierarchies. First described in the domestic chicken (Schjelderup-Ebbe, 1922), a social hierarchy is a system where individuals organize themselves into a particular, often linear, order of status from dominant to subordinate individuals. Hierarchies are frequently established by aggression or by body size and weight (Rubenstein and Abbot, 2017), and communicated visually (Campderrich et al., 2017; Grosenick et al., 2007) and chemically (Bigiani et al., 2005). Socially dominant individuals gain advantages that can increase their fitness, for instance they have access to more food (Hahn and Bauer, 2008) or have lower risks of predation (Teichroeb et al., 2015). Dominants also secure access to territory and partners for reproduction (Holekamp and Strauss, 2020) and have enhanced access to helpers in species with cooperative breeding (Dawson and Mannan, 1991). This apparently ideal situation also, however, comes with some costs, especially because access to this specific rank involves stressful situations, such as fights for dominance. Hence, gaining and retaining status, but also being a subordinate, may all cause stress. Consequently, social status has been found to be tightly linked to stress levels in various animal species, as measured by tissue glucocorticoid concentrations (Abbott et al., 2003; Ejike and Schreck, 50 1980).

Fish represent a very interesting group to investigate the extent to which glucocorticoid levels underscore social status, since they exhibit widely differing degrees of social organization (Wilson, 2000). They vary from isolation with rare social contact (e.g. swordfish Xiphias gladius (Palko et al., 1981)), to territorial individuals protecting an area amid conspecifics (Sogawa et al., 2016), to loosely coordinated shoaling (e.g. stickleback Gasterosteus aculeatus (Ginnaw et al., 2020)), to highly organized schooling (e.g. a tropical damselfish Chromis viridis (Nadler et al., 2018)). Although this myriad of social organization systems might be an advantage in studying links between physiology and behavior, the fact that fish species greatly vary in their life history traits might also obscure any underlying patterns. For example, Baker et al. (Baker et al., 2013) reported higher basal glucocorticoid concentrations for dominant individuals in four tests but the opposite in five other tests. The authors identified confounding factors that were fish density, wild versus captive animals, and level of aggressiveness (Baker et al., 2013). 
of directional patterns. In addition, our understanding of the potential biotic and abiotic factors affecting patterns is limited.

Plasma cortisol is an established indicator of stress in fishes (Mommsen et al., 1999; Sadoul and Geffroy, 2019), produced by the Hypothalamus-Pituitary-Interrenal (HPI) axis, it plays a key role in energy mobilization to cope with stressful events (Sadoul and Vijayan, 2016) but it may also have multiple other impacts, notably on reproduction (Rousseau et al., 2021) or sex determination (Geffroy and Douhard, 2019). Basal circulating cortisol titer can vary in response to life-history (Ricklefs and Wikelski, 2002), body condition (Breuner and Hahn, 2003) and season (Landys et al., 2006; Love et al., 2005). Since fishes are ectotherms, temperature is a major effector of their general metabolism (Stevens and Fry, 2011), including the production of cortisol (Alfonso et al., 2020). Intra-specific differences in basal cortisol may be genetically driven (Samaras and Pavlidis, 2018) and generally covary with differences in behavior, metabolism and lifehistory traits, as part of the well described 'coping style' (Koolhaas et al., 1999).

Consequently, an increase in cortisol production does not necessarily indicate a physiological "stress" stricto sensu (Schreck and Tort, 2016), but could be the result of a temperature-driven increase in metabolic rates (Alfonso et al., 2020). Intraspecific differences in cortisol levels could also be the result of genetically-driven differences in species overall metabolic rates. Therefore, distinguishing among stressful situations that actually trigger an increase in cortisol level (Harris, 2020) from those that are a consequence of differences in metabolic rates can be challenging. That is, differences in basal cortisol within a social hierarchy may be caused by the stress imposed by a specific social rank but, inversely, social rank might be the consequence of internal specificities of an individual. For ease of description, we refer to the first situation as the "stressenhanced hypothesis" and to the second as the "metabolic-enhanced hypothesis". Providing more information about external and internal effectors that affect relationships between basal cortisol level and social rank could ultimately provide support for these two hypotheses.

Here we test whether group size and life history traits can partially explain contrasting results about how social rank influences plasma cortisol. We tested the effect of external and internal factors, and particularly the effect of climate zone (tropical vs. temperate), to assess whether differences in cortisol between social ranks could also be due to the environment. A phylogenetically controlled meta-analysis and meta-regression were conducted to verify these hypotheses, and also to estimate the extent to which life history 
traits can modulate the relationship. In particular, beyond exploring how group size and

100 temperature would affect the correlation between basal cortisol production and social rank (i.e. effect size), we also considered other moderators such as fish size, sex, age, reproduction type and salinity.

103

\section{Methods}

105 (a) Literature search and study selection

106 We screened Web of Science for papers published before June $24^{\text {th }} 2020$ containing the 107 terms "subordinate" OR “dominant" OR “dominance” AND "fish" AND “cortisol” AND 108 "stress". We obtained 165 studies, from which we retained 73 that measured basal plasma cortisol in groups of fish with established hierarchies, in the Preferred Reporting Items

110 for Systematic Reviews and Meta-Analyses (PRISMA) checklist (Appendix A, 111 supplementary Figure 1).

(b) Estimating effect sizes

114 Statistical results $\left(\mathrm{r}, \mathrm{t}, \mathrm{F}, \chi^{2}, \mathrm{z}\right)$ were extracted directly from text or figures and, when not 115 directly available, results were converted into statistical tests $(n=7)$. One study was 116 removed because direction of the effect was not known, leading to a total of 72 studies.

117 In most instances, a Pearson's product-moment correlation coefficient, $r$, was provided 118 and used as our measure of effect size, when cortisol values concerned at least three 119 individuals in the study. In all other cases, we followed a recognized methodology by 120 Rosenthal (1991) (Rosenthal, 1991) to estimate $r$ using published statistics. This 121 calculation uses mean and variance of treatments, statistical results $\left(\mathrm{t}, \mathrm{F}, \chi^{2}, \mathrm{z}\right)$, and $\mathrm{p}$ 122 values reported with sample sizes, in respective order of preference. The calculation was 123 performed so that a positive relationship between cortisol values and rank order returned 124 a positive $r$, meaning that subordinates have higher cortisol than dominants. Generally, $r$ 125 values above 0.5 are considered to reflect large effect sizes in ecology (Cohen, 1992; 126 Jennions and Møller, 2002). For further analyses, $r$-values were transformed to Fisher's $127 z$, to improve normality (Koricheva et al., 2013).

129 (c) Meta-analyses using random effects 
130 We used hierarchical linear mixed-effects meta-analysis to test for both overall effect sizes and the importance of our moderators (Nakagawa and Santos, 2012) using the package 'metafor' v. 2.1-0 (Viechtbauer, 2010) in R v. 3.5.2. The overall effect sizes (i.e., mean of the effect sizes weighted by the inverse of their variance) were considered significant if their 95\% confidence intervals (CI) did not include zero (Koricheva et al., 2013). We used model selection based on the Akaike information criterion to determine which random factors should be included in each meta-analysis (Nakagawa and Santos, 2012). Non-independence of effect sizes within and among studies was accounted for by including i) the number of effect sizes collected "id" (which corresponds to the collected values) and ii) the "studies" (which corresponds to the reviewed article itself) as randomfactors. Phylogenetic non-independence across studies was handled by including relationships among species (Appendix A, supplementary Figure 2) as a random effect based on the Open Tree of Life database (Hinchliff et al., 2015), and Grafen's method providing a correlation matrix from branch length (Grafen and Hamilton, 1989). The R package 'rotl' v. 3.0.10 was used for this purpose (Michonneau et al., 2016)

Group size (dyadic contexts or group $>2$ ), reproduction type (monogamous, polygamous and polygynous), habitat temperature (temperate vs tropical), time since grouping (h) and fish weight (g, square-root transformed) were considered as moderators of effect size. We tested for multi-collinearity among moderators and the highest variance inflation factor was 2.26, below the recognized threshold of 3 (Zuur et al., 2010). The factors salinity (freshwater $\mathrm{n}=67$, sea $\mathrm{n}=7$ and brackish $\mathrm{n}=4$ water) and $\operatorname{sex}$ (male $\mathrm{n}=23$, female $=7$, mixed group $n=31$ and ambisexual $n=1$ ) could not be considered owing to discrepancies in the numbers of effect sizes. We used a multi-model inference approach based on Akaike's criteria corrected for small sample sizes (AICc) (Burnham and Anderson, 2002). We first assessed the relative strengths of each candidate model by calculating its Akaike weight, to identify the most parsimonious model. A constant term (the intercept) was included in all models. We estimated the importance of a predictor by summing the Akaike weights of all models in which that candidate variable appeared, so ranking predictors in order of importance (Burnham and Anderson, 2002). All multi-model analyses were conducted using the MuMIn R package v. 1.40.0 (Barton, 2014).

162 We used the $I^{2}$ index as a measure of heterogeneity in effect sizes. The index represents

163 the proportion of total variation in the data that is not a consequence of sampling error 
164 (Higgins et al., 2003). We used an extended version of $I^{2}$ that partitions total heterogeneity 165 between the variation explained by the study identity and by the variation of the residuals.

166 The latter remains to be explained by our moderators (Nakagawa and Santos, 2012). We 167 calculated the degree of phylogenetic signal in our estimates of effect size using the 168 phylogenetic heritability index, $H^{2}$, which is the variance attributable to phylogeny in 169 relation to the total variance in the data (Nakagawa and Santos, 2012). $H^{2}$ is equivalent to 170 Pagel's $\lambda$ (Pagel, 1999), where higher values indicate stronger phylogenetic signals.

172 (e) Publication bias

173 We used Egger's regression to highlight any publication bias, because studies with low 174 sample sizes tend to be rejected due to their lower probability of finding significant effects

175 (Egger et al., 1997; Koricheva et al., 2013). The intercept of the regression is considered 176 to demonstrate publication bias when its estimate significantly differs from zero (Egger 177 et al., 1997). To overcome the non-independent nature of our data, we also applied the 178 Egger's regression test on the meta-analytic residuals (Nakagawa and Santos, 2012).

\section{3. Results}

The final dataset comprised 78 effect sizes, across 22 species, from 72 studies. Of all models tested ( $\mathrm{n}=11)$, the most parsimonious (intercept-only) was the one with both studies and number of effect sizes (categorical) as random factor $(\mathrm{AICc}=144.41)$, while adding the phylogeny resulted in the second most parsimonious ( $\mathrm{AICc}=146.57$ ). Therefore, to retain phylogenetic relatedness in our models, we performed all analyses using this latter model with three random factors. Overall and as predicted, the hierarchical rank (higher for subordinates) was strongly and positively correlated with cortisol (Fisher's $z=0.4546, \mathrm{CI}=0.26-0.65$, Figure 1). We found considerable variation among studies $\left(I_{\text {total }}^{2}=88.5 \%, I_{\text {studies }}^{2}=84.6 \%, I_{\text {residual }}=4 \%\right)$, which was expected because they were almost as numerous as effect sizes. The phylogenetic signal was weak $\left(H^{2}=4.4 \%\right)$. We found no evidence of publication bias (Egger's regression of effect sizes: Intercept $=1.1158, P=0.14$; Egger's regression of meta-analytic residuals: Intercept $=0.14, P=0.85$; Figure 2). Multi-model inference indicated that group size (pair or $>2$ ), habitat temperature (temperate or tropical) and body weight were the most important predictors of the magnitude of rank-cortisol relationship (Table 1). When cortisol was evaluated in a dyadic context, there was a stronger and more positive rank-cortisol 
197 relationship than when evaluated in groups. For example, dominants in groups sometimes 198 had higher basal cortisol than subordinates (Table 1 and Figure 3A). The difference in 199 basal cortisol between dominant and subordinates was also stronger and more positive in 200 fishes from temperate compared to tropical regions (Table 1 and Figure 3B). Finally, mean fish body weight was positively correlated to Fisher's $z$ (Table 1 and Figure 3C), such that the difference in basal cortisol across hierarchical ranks was highly and positively correlated with fish body weight. Importantly, this was true when testing these moderators alone or in the same model.

\section{Discussion}

208 Our data support the main hypothesis, that dominants generally exhibit lower basal 209 cortisol level than subordinates. This effect is, however, modulated by group size, habitat 210 temperature and fish size. We identified two main possible explanations for why cortisol 211 varies in such cases, the 'stress-enhanced hypothesis' where this would be due to stress 212 itself, or the 'metabolic-enhanced hypothesis' where this would be due to variation in 213 metabolic rates.

214 Since cortisol is recognized as the main stress hormone in fishes, the fact that dominants 215 generally produce less cortisol than subordinates was expected, as a consequence of the 216 "stress-enhanced hypothesis". Dominants are aggressive towards subordinates in order to 217 keep their status. All these aggressive acts are perceived as stressful events explaining the 218 difference in cortisol levels. Interestingly, we found that the cortisol differences between 219 dominant and subordinates were more prominent when groups are small. This is because in most tests performed in dyadic contexts, dominants presented lower cortisol levels than subordinates whereas, in tests performed in larger groups, dominants could actually exhibited slightly higher cortisol levels than subordinates. This reveals the complexity with which social hierarchies can elicit stress. Individuals in large groups may face more intense food competition (Borcherding et al., 2019), cannibalism (Naumowicz et al., 2017), susceptibility to capture (Thambithurai et al., 2018) and sex competition (Wacker et al., 2017), for example. All of these processes may stress fishes, but dominants can use their status to monopolise opportunities to improve fitness. In larger groups, such valuable status could also result in more frequent challenges by conspecifics, increasing the costs of retaining dominant status and resulting in higher relative stress levels. In addition, our results could also indicate that subordinates are relatively less stressed in groups. This 
would be the consequence of having the agressive behavior of the dominant fish shared amongst multiple subordinates. Altogether, these results support the "stress-enhanced

233 hypothesis": holding a particular status drives your stress levels, indicated by cortisol 234 values. The metabolism of dominant individuals is often, however, higher than that of 235 subordinates (Geffroy et al., 2016; Metcalfe et al., 1995). Basal cortisol levels are also 236 positively correlated with metabolism (Mommsen et al., 1999), and we might therefore expect that dominants would have higher cortisol values. The opposite was observed in our study, further supporting the "stress-enhanced hypothesis".

239 Our findings relative to group-size also provide a plausible hypothesis to explain why 240 cortisol would show opposite results depending on the reproductive strategy of a species 241 (protandry or protogyny). In such species, cortisol has a key role in sex determination 242 (Geffroy and Douhard, 2019), notably in many hermaphroditic reef fishes where social 243 interactions shape the dynamics of sex-change (Goikoetxea et al., 2017). Indeed, a 244 contribution of cortisol was demonstrated in two protogynous species where big males 245 monopolize harems (large groups of females), and an increase in cortisol is necessary for 246 dominant females to change into the male (Nozu and Nakamura, 2015; Todd et al., 2019).

247 On the other hand, the female dominant of small groups of protandrous fish (e.g. 248 clownfish) may be less stressed, and subordinate males would then remain males because 249 of the stress imposed by the female, although this remains to be fully demonstrated 250 (Olivotto and Geffroy, 2017). The fact that mating system (monogamous, polygamous 251 and polygynous) was not included in the most parsimonious model does not permit us to 252 extrapolate our results, since most protandrous fish are monogamous and most 253 protogynous fish are polygynous. More studies focusing on hermaphroditic fishes are, 254 clearly, required.

255 In any case, the fact that the difference between basal cortisol in dominants and 256 subordinates of large groups was lesser than in small groups argues for the 'stress257 enhanced hypothesis', where basal cortisol levels in dominants (and subordinates) is a 258 consequence of a physiological stress, not merely of metabolic rate.

259 We found that habitat temperature (temperate versus tropical) also shapes the relationship 260 between basal cortisol and social status. This would advocate for the "metabolicenhanced" hypothesis. In warmer habitats, fishes will generally have higher metabolic rates (Killen et al., 2016), reflecting direct thermodynamic effects on all biochemical and physiological processes (Cossins and Bowler, 1987). Rates of basal cortisol production are known to be stimulated by increased temperature within fish species (Goikoetxea et 
al., 2021). High background rates of basal cortisol production in all individuals at high temperatures may tend to obscure differences in production that reflect stress due to social rank, especially if these are relatively subtle. The higher metabolism of fishes in warm environments may also lead to higher overall activity levels and general aggressiveness (Biro et al., 2010; Colchen et al., 2017), and reduce the stability of hierarchies (Kochhann et al., 2015), which could also obscure inter-individual differences in basal cortisol production due to social rank. That is, subtle differences in the level of stress due to social rank might be easier to observe in fish with overall lower metabolic rates in cooler temperate habitats (Alfonso et al., 2020), especially if differences in rank are associated with greater relative differences in activity level or behavioral tendencies such as boldness.

276 The finding that mean weight of fish was positively correlated to the Fisher's $z$ might simply indicate that a difference in size between dominant and subordinates becomes more pronounced as mean size increases. Hence, cortisol differences between dominants and subordinates also increase with this size difference. This could be due to the fact that bigger dominant fish impose higher stress on subordinates. Size difference may also reflect differences in life-history stage, another factor known to influence basal cortisol (Love et al., 2005). Unfortunately, the exact size of fish at social ranks was rarely reported in the articles reviewed, so this remains an interesting topic for future study. After a dominance hierarchy is initiated by the formation of a group, cortisol should increase in all individuals. Cortisol levels are expected to stabilize and diverge once ranks are established. That led us to expect 'time since grouping' to be an important variable in our model but we did not observe this. This suggests that the hierarchy is established very readily in most instances and that differences in basal cortisol among social ranks are relatively consistent over time, or at least that the studies we used only began measuring cortisol once the hierarchy had been settled.

291 Overall, our phylogenetic meta-analysis provided strong support for the hypothesis that 292 dominant fish generally display lower baseline cortisol than subordinates, where high cortisol likely represents physiological stress. Nonetheless, it remains difficult to assess whether social status is a cause (due to stress) or a consequence (due to metabolic rate) of differences in basal cortisol levels among individuals. Our results seem to provide support for both stress-enhanced and metabolism-enhanced hypotheses, indicating that multiple contributing factors are probably at play. That is, there can be a contribution of both biotic (sociality and fish size) and abiotic (habitat temperature) factors. The 
establishment of a hierarchy triggers physiological stress but the degree of cortisol release

300 is accentuated or diminished by habitat temperature and its effects on metabolism. These

301 findings have major implications for our understanding of the ecology and sociality of

302 fishes.

304 Acknowledgements

305 We are grateful to Diogo S. Samia for advice on meta-analysis.

\section{Funding}

308 The study is supported by the project 3S (Seabass, Sex \& Stress, grant number

309 4320175237) and by FAP-DF (Process 24052018).

Bibliography

313 Abbott, D.H., Keverne, E.B., Bercovitch, F.B., Shively, C.A., Mendoza, S.P., Saltzman,

314 W., Snowdon, C.T., Ziegler, T.E., Banjevic, M., Garland, T., Sapolsky, R.M., 2003. Are subordinates always stressed? A comparative analysis of rank differences in cortisol levels among primates. Horm. Behav. 43, 67-82.

Alfonso, S., Gesto, M., Sadoul, B., 2020. Temperature increase and its effects on fish stress physiology in the context of global warming. J. Fish Biol.

319 https://doi.org/10.1111/jfb.14599

320 Baker, M.R., Gobush, K.S., Vynne, C.H., 2013. Review of factors influencing stress hormones in fish and wildlife. J. Nat. Conserv. 21, 309-318. https://doi.org/10.1016/j.jnc.2013.03.003 Barton, K., 2014. MuMIn: Multi-model inference. R package version 1.40.0. Bigiani, A., Mucignat-Caretta, C., Montani, G., Tirindelli, R., 2005. Pheromone reception in mammals, in: Reviews of Physiology, Biochemistry and Pharmacology, Reviews of Physiology, Biochemistry and Pharmacology. Springer, Berlin, Heidelberg, pp. 1-35. https://doi.org/10.1007/s10254-004-0038-0

Biro, P.A., Beckmann, C., Stamps, J.A., 2010. Small within-day increases in temperature affects boldness and alters personality in coral reef fish. Proc. R. Soc. B

330 Biol. Sci. 277, 71-77. https://doi.org/10.1098/rspb.2009.1346

331 Borcherding, J., Heubel, K., Storm, S., 2019. Competition fluctuates across years and seasons in a 6-species-fish community: empirical evidence from the field. Rev. Fish Biol. Fish. 29, 589-604. https://doi.org/10.1007/s11160-019-09567-X Breuner, C.W., Hahn, T.P., 2003. Integrating stress physiology, environmental change, and behavior in free-living sparrows. Horm. Behav. 43, 115-123. https://doi.org/10.1016/S0018-506X(02)00020-X Burnham, K.P., Anderson, D.R., 2002. Model selection and multimodel inference: a practical information-theoretic approach, 2nd edn. ed. Springer, New York, NY. https://doi.org/10.1016/j.ecolmodel.2003.11.004 
340 Campderrich, I., Liste, G., Estevez, I., 2017. The looks matter; aggression escalation

341 from changes on phenotypic appearance in the domestic fowl. PLOS ONE 12,

342 e0188931. https://doi.org/10.1371/journal.pone.0188931

343 Cohen, J., 1992. A power primer. Psychol. Bull. 112, 155-159.

344 Colchen, T., Teletchea, F., Fontaine, P., Pasquet, A., 2017. Temperature modifies

345 activity, inter-individual relationships and group structure in a fish. Curr. Zool. 63, 175-

346 183. https://doi.org/10.1093/cz/zow048

347 Cossins, A.R., Bowler, K., 1987. The direct effects of temperature changes, in: Cossins,

348 A.R., Bowler, K. (Eds.), Temperature Biology of Animals. Springer Netherlands,

349 Dordrecht, pp. 23-60. https://doi.org/10.1007/978-94-009-3127-5_2

350 Dawson, J.W., Mannan, R.W., 1991. Dominance Hierarchies and Helper Contributions

351 in Harris' Hawks. The Auk 108, 649-660. https://doi.org/10.2307/4088105

352 Egger, M., Smith, G.D., Schneider, M., Minder, C., 1997. Bias in meta-analysis

353 detected by a simple, graphical test. BMJ 315, 629-634.

354 Ejike, C., Schreck, C.B., 1980. Stress and Social Hierarchy Rank in Coho Salmon.

355 Trans. Am. Fish. Soc. 109, 423-426. https://doi.org/10.1577/1548-

356 8659(1980)109<423:SASHRI >2.0.CO;2

357 Geffroy, B., Bolliet, V., Bardonnet, A., 2016. Kleptoparasitism and aggressiveness are influenced by standard metabolic rate in eels. Physiol. Behav. 157, 165-169.

360 Ecol. Evol. 34, 628-640. https://doi.org/10.1016/j.tree.2019.02.012

361 Ginnaw, G.M., Davidson, I.K., Harding, H.R., Simpson, S.D., Roberts, N.W., Radford,

362 A.N., Ioannou, C.C., 2020. Effects of multiple stressors on fish shoal collective motion

363 are independent and vary with shoaling metric. Anim. Behav. 168, 7-17.

364 https://doi.org/10.1016/j.anbehav.2020.07.024

365 Goikoetxea, A., Sadoul, B., Blondeau-Bidet, E., Aerts, J., Blanc, M.-O., Parrinello, H.,

366 Barrachina, C., Pratlong, M., Geffroy, B., 2021. Genetic pathways underpinning hormonal stress responses in fish exposed to short- and long-term warm ocean temperatures. Ecol. Indic. 120, 106937. https://doi.org/10.1016/j.ecolind.2020.106937

Goikoetxea, A., Todd, E.V., Gemmell, N.J., 2017. Stress and sex: does cortisol mediate sex change in fish? Reproduction 154, R149-R160. https://doi.org/10.1530/REP-170408

372 Grafen, A., Hamilton, W.D., 1989. The phylogenetic regression. Philos. Trans. R. Soc.

373 Lond. B Biol. Sci. 326, 119-157. https://doi.org/10.1098/rstb.1989.0106

374 Grosenick, L., Clement, T.S., Fernald, R.D., 2007. Fish can infer social rank by observation alone. Nature 445, 429-432. https://doi.org/10.1038/nature05511 Hahn, S., Bauer, S., 2008. Dominance in feeding territories relates to foraging success and offspring growth in brown skuas Catharacta antarctica lonnbergi. Behav. Ecol. Sociobiol. 62, 1149-1157. https://doi.org/10.1007/s00265-007-0543-7 Harris, B.N., 2020. Stress hypothesis overload: 131 hypotheses exploring the role of stress in tradeoffs, transitions, and health. Gen. Comp. Endocrinol. 288, 113355. https://doi.org/10.1016/j.ygcen.2019.113355

Higgins, J.P.T., Thompson, S.G., Deeks, J.J., Altman, D.G., 2003. Measuring inconsistency in meta-analyses. BMJ 327, 557-560.

https://doi.org/10.1136/bmj.327.7414.557

Hinchliff, C.E., Smith, S.A., Allman, J.F., Burleigh, J.G., Chaudhary, R., Coghill, L.M., Crandall, K.A., Deng, J., Drew, B.T., Gazis, R., Gude, K., Hibbett, D.S., Katz, L.A., Laughinghouse, H.D., McTavish, E.J., Midford, P.E., Owen, C.L., Ree, R.H., Rees, J.A., Soltis, D.E., Williams, T., Cranston, K.A., 2015. Synthesis of phylogeny and taxonomy into a comprehensive tree of life. Proc. Natl. Acad. Sci. 112, 12764-12769. 
https://doi.org/10.1073/pnas.1423041112

391 Holekamp, K.E., Strauss, E.D., 2020. Reproduction Within a Hierarchical Society from

392 a Female's Perspective. Integr. Comp. Biol. 60, 753-764.

393 https://doi.org/10.1093/icb/icaa068

394 Jennions, M., Møller, A.P., 2002. How much variance can be explained by ecologists

395 and evolutionary biologists? Oecologia 132, 492-500. https://doi.org/10.1007/s00442-

396 002-0952-2

397 Killen, S.S., Glazier, D.S., Rezende, E.L., Clark, T.D., Atkinson, D., Willener, A.S.T.,

398 Halsey, L.G., 2016. Ecological Influences and Morphological Correlates of Resting and

399 Maximal Metabolic Rates across Teleost Fish Species. Am. Nat. 187, 592-606.

400 https://doi.org/10.1086/685893

401 Kochhann, D., Campos, D.F., Val, A.L., 2015. Experimentally increased temperature

402 and hypoxia affect stability of social hierarchy and metabolism of the Amazonian

403 cichlid Apistogramma agassizii. Comp. Biochem. Physiol. A. Mol. Integr. Physiol. 190,

404 54-60. https://doi.org/10.1016/j.cbpa.2015.09.006

405 Koolhaas, J.M., Korte, S.M., De Boer, S.F., Van Der Vegt, B.J., Van Reenen, C.G.,

406 Hopster, H., De Jong, I.C., Ruis, M.A.W., Blokhuis, H.J., 1999. Coping styles in

407 animals: current status in behavior and stress-physiology. Neurosci. Biobehav. Rev. 23,

408 925-935. https://doi.org/10.1016/S0149-7634(99)00026-3

409 Koricheva, J., Gurevitch, J., Mengersen, K., 2013. Handbook of meta-analysis in

410 ecology and evolution. Princeton University Press, Princeton, New Jersey.

411 Landys, M.M., Ramenofsky, M., Wingfield, J.C., 2006. Actions of glucocorticoids at a

412 seasonal baseline as compared to stress-related levels in the regulation of periodic life

413 processes. Gen. Comp. Endocrinol. 148, 132-149.

414 https://doi.org/10.1016/j.ygcen.2006.02.013

415 Love, O.P., Chin, E.H., Wynne-Edwards, K.E., Williams, T.D., 2005. Stress Hormones:

416 A Link between Maternal Condition and Sex-Biased Reproductive Investment. Am.

417 Nat. 166, 751-766. https://doi.org/10.1086/497440

418 Metcalfe, N.B., Taylor, A.C., Thorpe, J.E., 1995. Metabolic rate, social status and life-

419 history strategies in Atlantic salmon. Anim. Behav. 49, 431-436.

420 https://doi.org/10.1006/anbe.1995.0056

421 Michonneau, F., Brown, J.W., Winter, D.J., 2016. rotl: an R package to interact with the Open Tree of Life data. Methods Ecol. Evol. 7, 1476-1481.

https://doi.org/10.1111/2041-210X.12593

Mommsen, T.P., Vijayan, M.M., Moon, T.W., 1999. Cortisol in teleosts: dynamics, mechanisms of action, and metabolic regulation. Rev. Fish Biol. Fish. 9, 211-268.

426 https://doi.org/10.1023/A:1008924418720

427 Nadler, L.E., Killen, S.S., Domenici, P., McCormick, M.I., 2018. Role of water flow

428 regime in the swimming behaviour and escape performance of a schooling fish. Biol.

429 Open 7. https://doi.org/10.1242/bio.031997

430 Nakagawa, S., Santos, E.S.A., 2012. Methodological issues and advances in biological meta-analysis. Evol. Ecol. 26, 1253-1274. https://doi.org/10.1007/s10682-012-9555-5

Naumowicz, K., Pajdak, J., Terech-Majewska, E., Szarek, J., 2017. Intracohort cannibalism and methods for its mitigation in cultured freshwater fish. Rev. Fish Biol. Fish. 1, 193-208. https://doi.org/10.1007/s11160-017-9465-2

Nozu, R., Nakamura, M., 2015. Cortisol Administration Induces Sex Change from Ovary to Testis in the Protogynous Wrasse, \&lt;b\&gt;\&lt;i\&gt;Halichoeres trimaculatus\&lt;/i\&gt;\&lt;/b\&gt; Sex. Dev. 9, 118-124.

439 Olivotto, I., Geffroy, B., 2017. Clownfish, in: Calado, R., Olivotto, I., Oliver, M.P., 
Holt, G.J. (Eds.), Marine Ornamental Species Aquaculture. John Wiley \& Sons, Ltd, pp.

441 177-199. https://doi.org/10.1002/9781119169147.ch12

442 Pagel, M., 1999. Inferring the historical patterns of biological evolution. Nature 401,

443 877-884. https://doi.org/10.1038/44766

444 Palko, B.J., Beardsley, G.L., Richards, W.J., 1981. Synopsis of the biology of the swordfish, Xiphias gladius Linnaeus. NOAA Tech. Rep.

Ricklefs, R.E., Wikelski, M., 2002. The physiology/life-history nexus. Trends Ecol. Evol. 17, 462-468. https://doi.org/10.1016/S0169-5347(02)02578-8

Rosenthal, R., 1991. Meta-analytic procedures for social research, Rev. ed, Metaanalytic procedures for social research, Rev. ed. Sage Publications, Inc, Thousand Oaks, CA, US. https://doi.org/10.4135/9781412984997

Rousseau, K., Prunet, P., Dufour, S., 2021. Special features of neuroendocrine interactions between stress and reproduction in teleosts. Gen. Comp. Endocrinol. 300, 113634. https://doi.org/10.1016/j.ygcen.2020.113634

Rubenstein, D.R., Abbot, P., 2017. Comparative Social Evolution. Cambridge University Press.

Sadoul, B., Geffroy, B., 2019. Measuring cortisol, the major stress hormone in fishes. J. Fish Biol. 94, 540-555. https://doi.org/10.1111/jfb.13904

Sadoul, B., Vijayan, M.M., 2016. 5 - Stress and Growth, in: Carl B. Schreck, L.T., Anthony P. Farrell and Colin J. Brauner (Ed.), Fish Physiology, Biology of Stress in FishFish Physiology. Academic Press, pp. 167-205.

461 Samaras, A., Pavlidis, M., 2018. Regulation of divergent cortisol responsiveness in

462 European sea bass, Dicentrarchus labrax L. PLOS ONE 13, e0202195.

463

464

465

466

467

468

469

470

471

472

473 https://doi.org/10.1371/journal.pone.0202195

Schjelderup-Ebbe, T., 1922. Contributions to the social psychology of the domestic chicken. Repr. Z. Fuer Psychol. 88, 225-252.

Schreck, C.B., Tort, L., 2016. 1 - The Concept of Stress in Fish, in: Schreck, C.B., Tort, L., Farrell, A.P., Brauner, C.J. (Eds.), Fish Physiology, Biology of Stress in Fish. Academic Press, pp. 1-34. https://doi.org/10.1016/B978-0-12-802728-8.00001-1

Sogawa, S., Ota, K., Kohda, M., 2016. A dear enemy relationship in a territorial cichlid: evidence for the threat-level hypothesis. Behaviour 153, 387-400.

https://doi.org/10.1163/1568539X-00003351 Stevens, E.D., Fry, F.E.J., 2011. Heat transfer and body temperatures in nonthermoregulatory teleosts. Can. J. Zool. https://doi.org/10.1139/z74-152 Teichroeb, J.A., White, M.M.J., Chapman, C.A., 2015. Vervet (Chlorocebus pygerythrus) Intragroup Spatial Positioning: Dominants Trade-Off Predation Risk for Increased Food Acquisition. Int. J. Primatol. 36, 154-176. https://doi.org/10.1007/s10764-015-9818-4 Thambithurai, D., Hollins, J., Leeuwen, T.V., Rácz, A., Lindström, J., Parsons, K., Killen, S.S., 2018. Shoal size as a key determinant of vulnerability to capture under a simulated fishery scenario. Ecol. Evol. 8, 6505-6514. https://doi.org/10.1002/ece3.4107 Todd, E.V., Ortega-Recalde, O., Liu, H., Lamm, M.S., Rutherford, K.M., Cross, H., Black, M.A., Kardailsky, O., Graves, J.A.M., Hore, T.A., Godwin, J.R., Gemmell, N.J., 2019. Stress, novel sex genes, and epigenetic reprogramming orchestrate socially controlled sex change. Sci. Adv. 5, eaaw7006. https://doi.org/10.1126/sciadv.aaw7006 Viechtbauer, W., 2010. Conducting meta-analyses in R with the metafor package. J. Stat. Softw. 36, 1-48.

Wacker, S., Ness, M.H., Östlund-Nilsson, S., Amundsen, T., 2017. Social structure affects mating competition in a damselfish. Coral Reefs 36, 1279-1289. https://doi.org/10.1007/s00338-017-1623-4 
Wilson, E.O., 2000. Sociobiology: The New Synthesis, Twenty-Fifth Anniversary

491 Edition. Harvard University Press.

492 Zuur, A.F., Ieno, E.N., Elphick, C.S., 2010. A protocol for data exploration to avoid

493 common statistical problems. Methods Ecol. Evol. 1, 3-14.

494 https://doi.org/10.1111/j.2041-210X.2009.00001.x

495

496

497

498

499

500

501

502

503

504

505

Figure Captions

506

507 Figure 1. Forest plot of the social rank-cortisol effect sizes. Effect sizes are shown in ascending order. Filled circles with horizontal lines represent effect size $\pm 95 \%$ confidence intervals. The overall and significant effect size is represented by a diamond.

511 Figure 2. Funnel plots of the meta-analyse using both the effect sizes and the meta512 analytic residuals of the best model.

514 Figure 3. Effects of (A) group size, (B) temperature and (C) mean fish size on the social 515 rank-cortisol relationship (Fisher's $z$ ). Plots (A) and (B) show mean $\pm 95 \%$ confidence 516 intervals. The number of species tested at each factor level is shown in the bottom of 517 plots. 
534 Table 1. Summary of the multi-model inference conducted to explain variation in the 535 social rank-cortisol in fish

\begin{tabular}{lllll}
\hline Predictor & Levels & Estimate & S.E. & $\boldsymbol{z}$-value \\
\hline Intercept & & 0.5 & 0.34 & 1.49 \\
Group size & Paired & 0.28 & 0.14 & $1.98^{*}$ \\
Species body size & & 0.028 & 0.014 & $2.12^{*}$ \\
Environment & \multirow{2}{*}{ Tropical } & -0.67 & 0.32 & $-2.08^{*}$ \\
\hline
\end{tabular}

536 Estimates are average coefficients of the model, their associated standard error (S.E). * 537 indicates a p-value $<0.05$. 